\title{
Estudo da vulnerabilidade natural da sub-bacia do Rio Piracicaba/MG utilizando Sistemas de Informações Geográficas (SIG)
}

A crescente urbanização desordenada que vem ocorrendo no Brasil, tem provocado um aumento na pressão sobre os recursos hídricos, além de produzir alterações no ciclo hidrológico. Nesse contexto, perante às diversas pressões exercidas em uma bacia hidrográfica, torna-se necessário a avaliação de sua vulnerabilidade natural o que permite o planejamento ambiental na área. A sub-bacia do rio Piracicaba/MG, afluente da margem esquerda do rio Doce, apresenta alto grau de antropização e concentra atividades econômicas importantes, com destaque para atividades minerárias. Desta forma, este trabalho tem por objetivo elaborar um mapa de vulnerabilidade natural para a sub-bacia do rio Piracicaba/MG, considerando as variáveis geologia, pedologia, declividade e cobertura vegetal. Para elaboração do mapa de vulnerabilidade da sub-bacia do rio Piracicaba/MG foi utilizado o Sistema de Informações Geográficas (SIG), como ferramenta de análise dos fatores que definem a vulnerabilidade da bacia. A metodologia utilizada foi a análise multicritério, por meio da álgebra de mapas, empregando pesos para cada classe obtida nos elementos considerados (geologia, pedologia, declividade e cobertura vegetal), que variam de 1 a 5 , considerando o grau de vulnerabilidade à erosão. Os resultados encontrados apontaram que a área com maior vulnerabilidade natural está situada no alto curso do rio Piracicaba, indicando que esta área deve ser prioritária para conservação.

Palavras-chave: Rio Piracicaba; Vulnerabilidade natural; Análise multicritério; Álgebra de mapas; Minas Gerais.

\section{Study of the natural vulnerability of the hydrographic sub-basin of the Piracicaba/MG River using Geographical Information Systems} (GIS)

\begin{abstract}
The growing disordered urbanization that has been occurring in Brazil has caused an increase in the pressure over water resources, besides producing changes in the hydrological cycle. In this context, due to all the pressures exerted in a river basin it is necessary to evaluate its natural vulnerability, allowing a proper environmental planning in the area. The sub-basin of the Piracicaba/MG river, affluent of the left bank of the Doce river, presents a high degree of anthropization and concentrates important economic activities, with emphasis on mining activities. Therefore, this work aims to elaborate a map of natural vulnerability for the sub-basin of the Piracicaba/MG river, considering the variables: geology, pedology, slope and vegetation cover. The Geographic Information System (GIS) was used as a tool to analyze the factors that define the vulnerability of the basin. A multicriteria analysis was performed in which map algebra was used. In this work, each class obtained in the considered elements (geology, pedology, slope and vegetation cover) received points, ranging from 1 to 5 , considering the degree of vulnerability to erosion. The obtained results showed the area with the greatest natural vulnerability. It is located in the upper course of the Piracicaba river, indicating that this area should be a conservation priority area.
\end{abstract}

Keywords: Piracicaba river; Natural vulnerability; Multicriteria analysis; Map álgebra; Minas Gerais

Topic: Engenharia da Sustentabilidade e Meio Ambiente

Reviewed anonymously in the process of blind peer.
Received: 10/02/2019

Approved: 25/03/2019
Leilane Junqueira Fraga Sokoloski (iD Universidade Federal de Itajubá, Brasil http://lattes.cnpq.br/4427574917577715 http://orcid.org/0000-0001-5554-3684 leilanejf@yahoo.com.br

Marcela Roberta Almeida Ferreira Universidade Federal de Itajubá, Brasil http://lattes.cnpq.br/7624777035898355 marcelaroberta@hotmail.com

Gabriel Andrade Viterbo

Universidade Federal de Itajubá, Brasil http://lattes.cnpq.br/6886957426525164 gabrielviterbo@hotmail.com

DOI: 10.6008/CBPC2179-6858.2019.002.0018

\author{
Fernanda Maria Belotti \\ Universidade Federal de Itajubá, Brasil \\ http://lattes.cnpq.br/5777360077113950 \\ fernandabelotti@unifei.edu.br \\ Eliane Maria Vieira (iD \\ Universidade Federal de Itajubá, Brasil \\ http://lattes.cnpq.br/5997337541777088 \\ http://orcid.org/0000-0003-1749-6105 \\ elianemv@yahoo.com.br
}

Referencing this:

SOKOLOSKI, L. J. F.; FERREIRA, M. R. A.; VITERBO, G. A.; BELOTTI, F. M.; VIEIRA, E. M.. Estudo da vulnerabilidade natural da sub-bacia do Rio Piracicaba/MG utilizando Sistemas de Informações Geográficas (SIG). Revista Ibero Americana de Ciências Ambientais, v.10, n.2, p.211222, 2019. DOI: http://doi.org/10.6008/CBPC21796858.2019.002.0018 


\section{INTRODUÇÃO}

A crescente urbanização desordenada que vem ocorrendo no Brasil, tem provocado um aumento na pressão sobre os recursos hídricos, além de produzir alterações no ciclo hidrológico da água. Perante às diversas pressões exercidas, em um contexto de bacia hidrográfica, torna-se necessário a avaliação de sua vulnerabilidade, permitindo um diagnóstico sobre o estado do meio.

O termo vulnerabilidade é utilizado para designar o "grau de suscetibilidade em que um componente do meio, de um conjunto de componentes ou de uma paisagem apresentam em resposta a uma ação, atividade ou fenômeno" (SANTOS, 2007). A vulnerabilidade natural está associada às condicionantes do meio físico, podendo ser entendida como a capacidade do ambiente em reagir a fatores naturais relacionados com a morfogênese e a pedogênese (KLAIS et al., 2012, citado por SANTOS, 2014). Desta forma, a elaboração de cartas de vulnerabilidade, é um importante instrumento para o planejamento ambiental, uma vez que permitem o planejamento e a gestão de maneira eficiente para a conservação, em especial dos recursos hídricos (SANTOS, 2014).

O planejamento ambiental tem por objetivo estabelecer normas para territórios complexos, por meio da interpretação do meio como um todo (SANTOS, 2009). O êxito de estudos neste sentido depende dos elementos definidos para serem abordados, sendo que geologia, pedologia, cobertura vegetal e estudos de geomorfologia e seus derivados, como a declividade, são recorrentes (SANTOS, 2009).

Segundo Santos (2009) a maior parte dos estudos de planejamento ambiental apresenta dados referentes à geologia, fornecendo informações litológicas e estruturais do substrato rochoso, subsidiando as interpretações sobre o relevo, solo, processos erosivos, dentre outros. A declividade também está associada aos processos erosivos, exercendo influência sobre o escoamento superficial da água; pode ser caracterizada pela inclinação que a superfície do terreno possui em relação ao plano horizontal em que se encontra (LOPES, 2015). Outro importante fator associado ao fenômeno de erosão e assoreamento, cuja compreensão é primordial ao planejamento ambiental, são os tipos de solos (pedologia) (SANTOS, 2009).

Ainda, em relação à tomada de decisão relativa à conservação de ecossistemas naturais para o planejamento ambiental, o mapeamento da cobertura vegetal é de extrema importância, uma vez que, promove a caracterização da morfodinâmica da unidade de paisagem e infere sua capacidade de proteção (FLORENZANO, 2008, citado por LOPES, 2015).

Segundo Costa Neto (2010), o principal instrumento para gestão do território é o zoneamento; que também é integrante do processo de gestão dos recursos hídricos, sendo que para sua implementação é necessário que se realize uma série de estudos e levantamentos como subsídio para tomada de decisão para o gerenciamento da água e seus usos múltiplos. De acordo com a Política Nacional de Recursos Hídricos (PNRS) (BRASIL, 1997) a bacia hidrográfica é a unidade de planejamento e de gestão dos recursos hídricos, e como uma fase no processo de gestão, a definição da vulnerabilidade deste território mostra-se importante no sentido de subsidiar a tomada de decisão para seu gerenciamento adequado. 
A sub-bacia do rio Piracicaba/MG, afluente do rio Doce, pode ser caracterizada pelas atividades de extração de recursos minerais, siderurgia e silvicultura, associada às indústrias de carvão e celulose (CBHDOCE, 2010). A sub-bacia abriga o maior complexo siderúrgico da América Latina, com destaque para a Companhia Siderúrgica Belgo Mineira, a Aperam South América e as Usinas Siderúrgicas de Minas Gerais S.A. (Usiminas), empresas de mineração, com destaque para a Vale S.A., além de empresas reflorestadoras, que cultivam o eucalipto para fornecer matéria-prima para as indústrias de celulose (CBH-DOCE, 2010).

Neste contexto, visto a importância desta bacia pela presença de atividades econômicas de interesse, este trabalho tem por objetivo elaborar um mapa de vulnerabilidade natural para a sub-bacia do rio Piracicaba/MG, por meio da integração entre os diagnósticos sobre suas fragilidades para os elementos geologia, pedologia, declividade e cobertura vegetal; contribuindo com estudos sobre planejamento ambiental e a preservação dos recursos hídricos.

\section{MATERIAIS E MÉTODOS}

A bacia hidrográfica do rio Doce está situada no Sudeste do Brasil, pertencendo aos estados de Minas Gerais (86\%) e do Espírito Santo (14\%) (CBH-DOCE, 2010). A sub-bacia do rio Piracicaba/MG, afluente da margem esquerda do rio Doce (figura 1), possui uma área de $5.681 \mathrm{~km}^{2}$, encontrando-se totalmente inserida no Estado de Minas Gerais, nas mesorregiões Metropolitana de Belo Horizonte e Vale do Rio Doce e, nas microrregiões Itabira e Ipatinga (CBH-DOCE, 2010). De acordo com o Plano Integrado de Recursos Hídricos (PIRH) da Bacia Hidrográfica do rio Doce (2010) o rio Piracicaba é o principal curso d'água da região, sendo suas nascentes localizadas no município de Ouro Preto e este percorre cerca de $241 \mathrm{~km}$ até o rio Doce, na divisa dos municípios de Ipatinga/MG e Timóteo/MG.

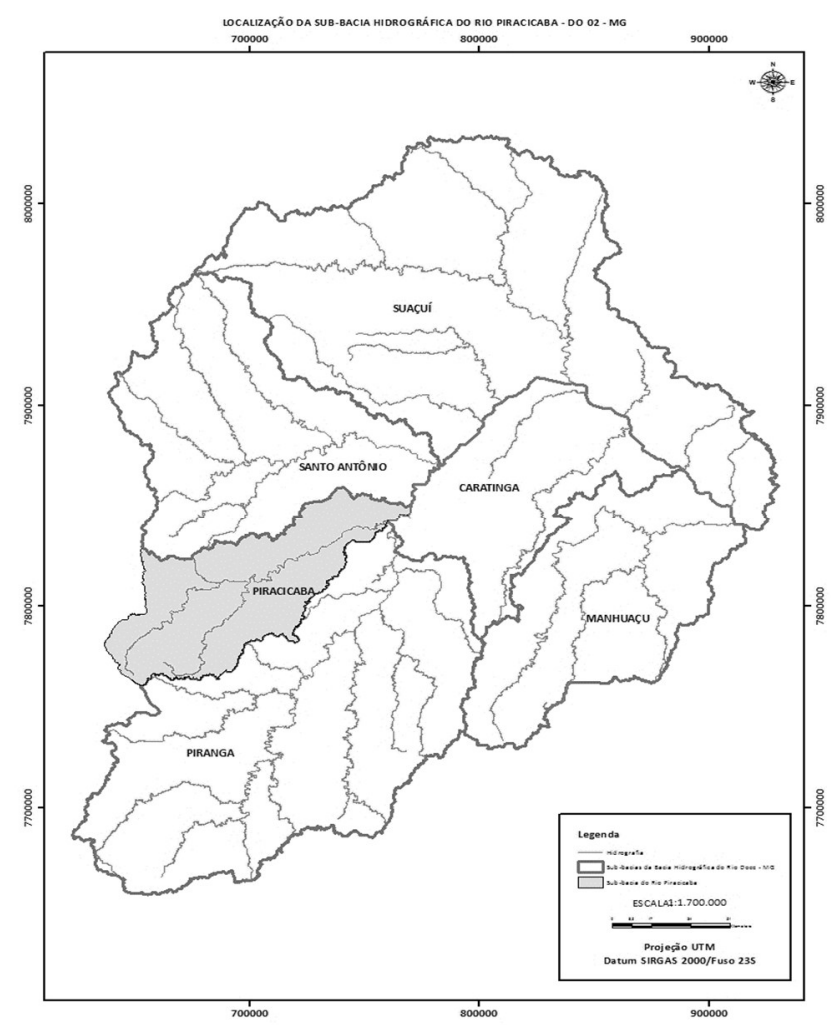

Figura 1: Localização da sub-bacia hidrográfica do Rio Piracicaba/MG em relação a bacia do rio Doce/MG. 
Para elaboração do mapa de vulnerabilidade da sub-bacia do rio Piracicaba/MG foi utilizado o Sistema de Informações Geográficas (SIG), como ferramenta de análise dos fatores que definem a vulnerabilidade da bacia. A metodologia utilizada foi a análise multicritério, por meio da álgebra de mapas e para a ponderação dos atributos foi feita uma adaptação dos pressupostos de Santos (2014).

Foram consideradas as seguintes variáveis, também de acordo com uma adaptação da metodologia de Santos (2014): geologia, pedologia, declividade e cobertura vegetal. Optou-se por utilizar tais variáveis em função da importância para o planejamento ambiental e territorial, levando em consideração aquelas mencionadas constantemente na literatura com potencial para expressar o grau vulnerabilidade natural do ambiente e ainda, aquelas que apresentavam base cartográfica disponível em uma escala que fosse detalhada para a área de estudo, uma vez que, se trata de uma sub-bacia hidrográfica.

Assim, para cada classe utilizada (geologia, pedologia, declividade e cobertura vegetal) foi estabelecido um peso, variando de 1 a 5 , considerando o grau de vulnerabilidade à erosão. Desta forma quanto maior forem os pesos, mais elevado será o grau de vulnerabilidade natural da classe. Em relação à representação cartográfica da vulnerabilidade foram selecionadas cinco cores que variam do verde (menor índice de vulnerabilidade) ao vermelho (maior índice de vulnerabilidade), de modo a padronizar todos os mapas, conforme a tabela 1.

Tabela 1: Grau de vulnerabilidade natural de acordo com os pesos definidos.

\begin{tabular}{|l|l|}
\hline Peso & Grau de Vulnerabilidade \\
\hline 1 & Muito baixo \\
\hline 2 & Baixo \\
\hline 3 & Médio \\
\hline 4 & Alto \\
\hline 5 & Muito Alto \\
\hline
\end{tabular}

Fonte: Santos (2014).

Após a seleção das variáveis e aquisição das bases utilizadas, estas foram padronizadas no mesmo sistema de coordenadas empregando a Projeção UTM, Datum SIRGAS 2000 FUSO 23 Sul. Para cada variável foi elaborado um mapa de índice de vulnerabilidade utilizando o software ArcGis 10.3, conforme descrição metodológica a seguir.

\section{Geologia}

O mapa de geologia foi elaborado utilizando como base o mapa geológico do Estado de Minas Gerais, feito e disponibilizado em formato shapefile pela Companhia de Desenvolvimento Econômico do Estado de Minas Gerais (CODEMIG) no ano de 2013. As classes geológicas foram estratificadas de acordo com uma adaptação dos valores de vulnerabilidade estabelecidos por Crepani et al. (2001).

\section{Pedologia}

O mapa de pedologia foi elaborado utilizando como base o mapa de solos do Estado de Minas Gerais, feito pela Fundação Estadual de Meio Ambiente (FEAM) no ano de 2010 e disponibilizado em formato 
shapefile pelo Sistema Estadual de Meio Ambiente e Recursos Hídricos - SISEMA. As classes de solos foram estratificadas em função da propensão natural da classe de solo à erosão.

\section{Declividade}

O mapa de declividade foi elaborado através de um Modelo Digital de Elevação (MDE), com resolução espacial de $30 \times 30$ m, a partir de dados altimétricos da imagem Advanced Spaceborne Thermal Emission and Reflection Radiometer (ASTER), obtido do site do United States Geological Survey (USGS). Para elaboração do mapa foi feito o mosaico utilizando 4 imagens para recobrir toda área de estudo e posteriormente foi feito o recorte para o limite da sub-bacia, por meio do software ArcGis 10.3. Em seguida foi utilizada a ferramenta slope, para o cálculo da declividade em porcentagem.

\section{Cobertura vegetal}

Para a elaboração do mapa de cobertura vegetal foi utilizada como base as imagens do China-Brazil Earth Resources Satellite (CBERS) 4, disponibilizadas pelo Instituto Nacional de Pesquisas Espaciais (Inpe), bandas 5, 6 e 7 do sensor MUX, levando em consideração a data de obtenção e a qualidade da imagem. Para recobrir toda área de estudo foi feito um mosaico das imagens em que a sub-bacia está localizada e, posteriormente recortado para seu limite, por meio do software ArcGis 10.3. Em seguida, foi feita a análise de qualidade das imagem e processo de segmentação utilizando o software Spring versão 5.5.1. O arquivo segmentado foi novamente inserido no software ArcGis para realização de ajustes nos polígonos e a classificação dos mesmos por processo manual. De modo a obter um melhor resultado na classificação, foram adquiridas amostras no Google Earth para verificação, possibilitando sanar dúvidas a partir das imagens de alta resolução espacial disponíveis.

Em relação às classes de cobertura vegetal, ressalta-se que quanto mais próximo de seus limites de tolerância às variações dos fatores bióticos e abióticos, mais vulnerável a classe será (SANTOS, 2009). Neste estudo, quanto maior a interferência antrópica, incluindo os sistemas agrosilvopastoris, e a susceptibilidade à processos erosivos, maior será a vulnerabilidade da região, uma vez que, de acordo com Lopes (2015) a cobertura vegetal garante mais estabilidade ao solo, ao contrário das atividades antrópicas. Em relação à mineração, coube neste trabalho a definição de uma classe específica, já que a bacia possui intensa atividade minerária.

As áreas de implementação de silvicultura as quais estão bem representadas na área da bacia, devido à demanda das indústrias instaladas na região, que utilizam o carvão e celulose em seus processos produtivos, foram classificadas como mata, englobando tanto áreas nativas como áreas plantadas. Adotouse a classe solo exposto para as áreas onde haviam sido retiradas as culturas e áreas sem cobertura vegetal e agrossilvopastoril para áreas de manejo em ocorrência. Também foram classificadas como área urbana, comunidades, distritos industriais, e benfeitorias com áreas representativas.

Ademais, a delimitação da área de estudo utilizada para o recorte durante a confecção dos mapas foi feita utilizando o limite disponibilizado pela Agência Nacional de Águas (ANA). Após a execução dos processos 
descritos acima, os mapas gerados foram transformados para o formato raster e reclassificados utilizando a ferramenta reclassify do software ArcGis 10.3, considerando os pesos atribuídos (1 a 5). Assim, os dados resultantes foram submetidos a operação de álgebra de mapas, utilizando a equação 1.

Equação 1: Equação utilizada para a álgebra de mapas.

$$
\text { Vulnerabilidade natural }=\frac{G+P+D+C V}{4}
$$

A descrição metodológica do trabalho está sintetizada na figura 2.

$$
\begin{array}{r}
\text { Em que: } \\
\mathrm{G}=\text { Geologia; } \\
\mathrm{P}=\text { Pedologia; } \\
\mathrm{D}=\text { Declividade; } \\
\mathrm{CV}=\text { Cobertura Vegetal. }
\end{array}
$$

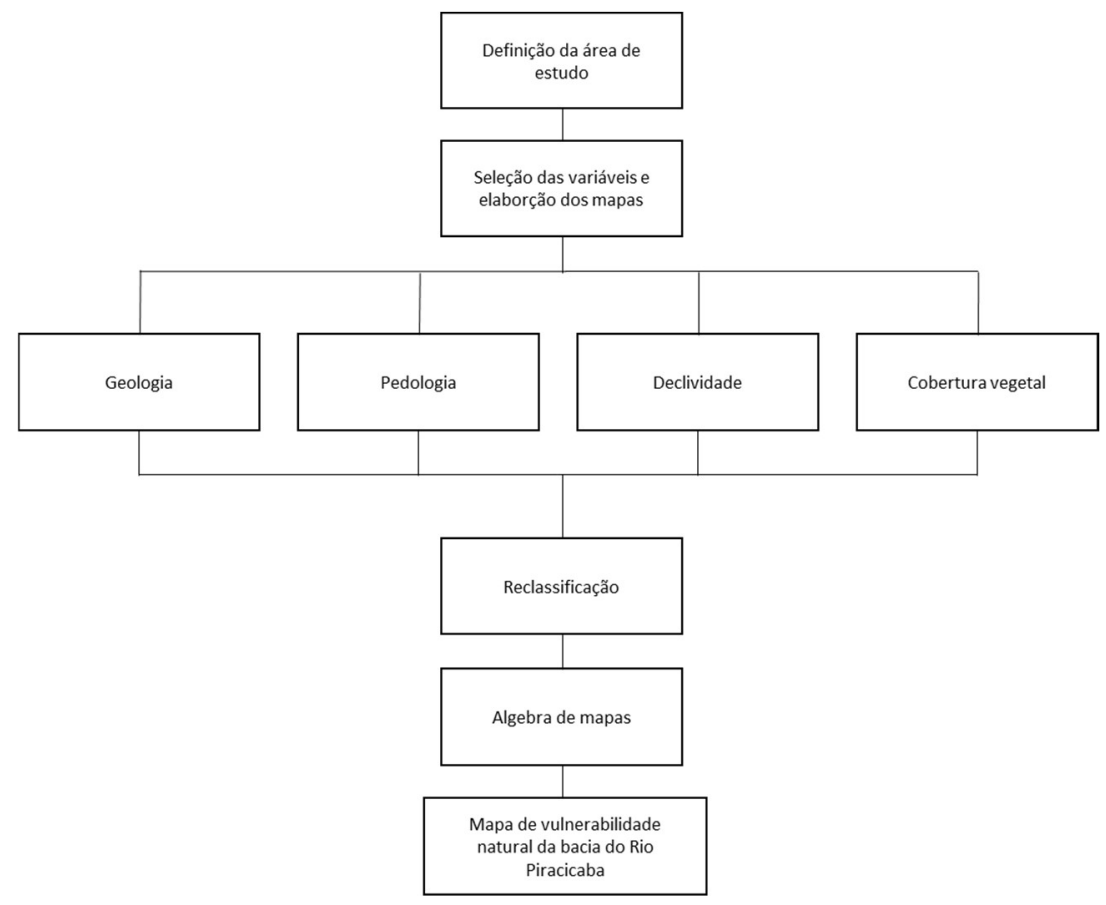

Figura 2: Descrição metodológica do trabalho.

\section{RESULTADOS E DISCUSSÃO}

A estratificação das classes para cada variável considerada neste trabalho (geologia, pedologia, declividade e cobertura vegetal), bem como os pesos definidos e os mapas gerados e reclassificados, estão apresentados a seguir. Para a variável geologia as classes definidas e seus respectivos pesos estão apresentados na tabela 2. Segundo Crepani et al. (2001) o grau de estabilidade das rochas é definido de acordo com o grau de coesão, sendo que, quanto maior a estabilidade, menor a vulnerabilidade em relação à geologia. A figura 3 representa o mapa do índice de vulnerabilidade para a variável geologia.

Para a sub-bacia do rio Piracicaba/MG foram identificadas distintas formações geológicas que conferiram graus de vulnerabilidade natural diferentes ao longo de toda bacia. Constatou-se que as áreas com maior vulnerabilidade estão concentradas principalmente no alto curso e próximo a foz do rio Piracicaba. De maneira geral, a geologia desta sub-bacia é composta pelo Quadrilátero Ferrífero e pelo Embasamento Cristalino, sendo que as rochas são agrupadas em quatro formações: Complexo Granitognáissico (embasamento) Supergrupo Rio das Velhas, Supergrupo Minas e Grupo Itacolomi; o Embasamento 
Cristalino é constituído por rochas cristalinas, com formação intrusiva, composto por rochas granito-gnaisses (CBH-DOCE, 2010). Todas as demais formações que ocorrem na área da sub-bacia do Rio Piracicaba/MG com exceção da área do Quadrilátero Ferrífero estão relacionadas aos complexos cristalinos (CBH-DOCE, 2010). Em relação à pedologia as classes definidas e seus respectivos pesos estão apresentados na tabela 3. A figura 4 representa o mapa do índice de vulnerabilidade para a variável pedologia.

Tabela 2: Grau de vulnerabilidade natural da sub-bacia do rio Piracicaba/MG em relação a geologia.

\begin{tabular}{|c|c|c|c|c|c|}
\hline Classes geológicas & Pesos & Classes geológicas & Pesos & Classes geológicas & Pesos \\
\hline $\begin{array}{l}\text { Quartzitos ou } \\
\text { Metaquartzitos }\end{array}$ & 1 & $\begin{array}{l}\text { Milonitos, Quartzo } \\
\text { Muscovita, Biotita, } \\
\text { Clorita Xisto }\end{array}$ & 2 & $\begin{array}{l}\text { Arenitos Quartzosos ou } \\
\text { Ortoquartzitos }\end{array}$ & 4 \\
\hline Riólito, Granito, Dacito & 1 & $\begin{array}{l}\text { Piroxenito, } \\
\text { Anfibolito } \\
\text { Kimberlito, Dunito }\end{array}$ & 3 & $\begin{array}{l}\text { Conglomerados, } \\
\text { Subgrauvacas }\end{array}$ & 4 \\
\hline $\begin{array}{l}\text { Granodiorito, } \\
\text { Quartzo Diorito, } \\
\text { Granulitos }\end{array}$ & 1 & $\begin{array}{l}\text { Hornblenda, } \\
\text { Tremolita, Actinolita } \\
\text { Xisto }\end{array}$ & 3 & Grauvacas, Arcózios & 5 \\
\hline Migmatitos, Gnaisses & 1 & $\begin{array}{l}\text { Estaurolita Xisto, } \\
\text { Xistos Granatíferos }\end{array}$ & 3 & Siltitos, Argilitos & 5 \\
\hline $\begin{array}{l}\text { Fonólito, Nefelina } \\
\text { Sienito, Traquito, } \\
\text { Sienito }\end{array}$ & 2 & Filito, Metassiltito & 3 & Folhelhos & 5 \\
\hline $\begin{array}{l}\text { Andesito, Diorito, } \\
\text { Basalto }\end{array}$ & 2 & Ardósia, Metargilito & 4 & $\begin{array}{l}\text { Calcários, Dolomitos, } \\
\text { Margas, Evaporitos }\end{array}$ & 5 \\
\hline $\begin{array}{l}\text { Anortosito, Gabro, } \\
\text { Peridotito }\end{array}$ & 2 & Mármores & 4 & $\begin{array}{l}\text { Sedimentos } \\
\text { Inconsolidados, } \\
\text { Aluviões, Colúvios, etc. }\end{array}$ & 5 \\
\hline
\end{tabular}

Fonte: Adaptado de Crepani et al. (2001).

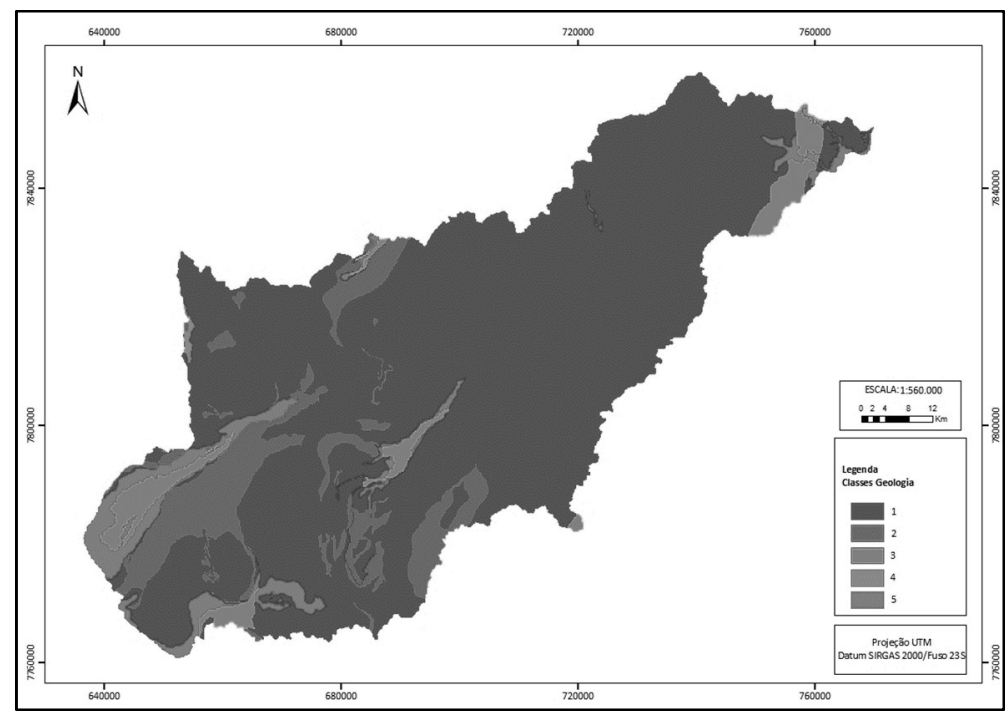

Figura 3: Mapa do índice de vulnerabilidade para a variável geologia da sub-bacia hidrográfica do rio Piracicaba/MG.

Tabela 3: Grau de vulnerabilidade natural da sub-bacia do rio Piracicaba/MG em relação à pedologia.

\begin{tabular}{|l|l|}
\hline Classes de Solos & Pesos \\
\hline $\begin{array}{l}\text { Latossolos - Latossolos Vermelhos, AAmarelos e Vermelho- } \\
\text { Amarelos. }\end{array}$ & 1 \\
\hline $\begin{array}{l}\text { Argissolos e Cambissolos - Cambissolo Háplico e Argissolos } \\
\text { Vermelho-Amarelo }\end{array}$ & 4 \\
\hline Neossolos Litólicos. & 5 \\
\hline
\end{tabular}




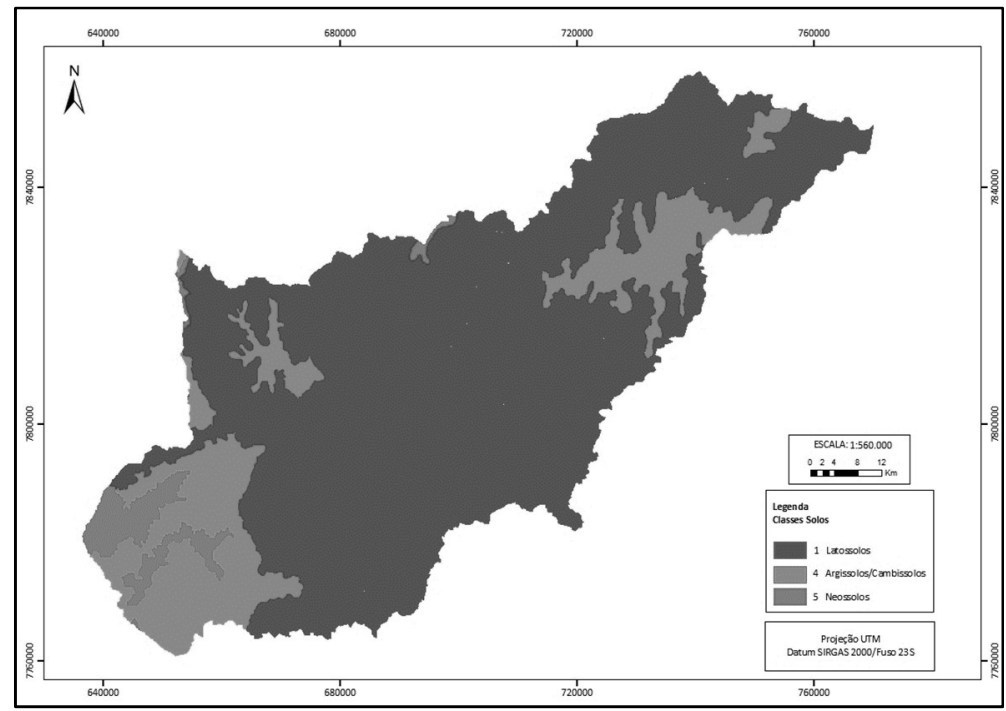

Figura 4: Mapa do índice de vulnerabilidade para a variável pedologia da sub-bacia hidrográfica do Rio Piracicaba/MG.

Em relação a pedologia, na sub-bacia do rio Piracicaba/MG, há uma predominância da classe de solo Latossolos e suas variações (Latossolos Vermelhos, Amarelos e Vermelho-Amarelos) seguido dos Argissolos e Cambissolos (Cambissolo Háplico, Argissolos Vermelho-Amarelo) e por fim os Neossolos Litólicos. Nota-se, como esperado, que assim como na geologia, houve uma predominância de altos graus de vulnerabilidade no alto curso do rio Piracicaba. A sub-bacia do rio Piracicaba/MG segue o mesmo padrão de solos presente na Bacia do rio Doce, onde predominam os Latossolos Vermelho Amarelos e os Argissolos Vermelhos (CBHDOCE, 2010).

Segundo Lopes (2015) os processos erosivos são predominantes em solos jovens e pouco desenvolvidos, já os solos maduros, profundos, lixiviados e bem desenvolvidos apresentam melhores condições de estabilidade. Os Latossolos de acordo com a Empresa Brasileira de Pesquisa Agropecuária (EMBRAPA) (2006), são solos fortemente intemperizados, profundos, friáveis e porosos, de ocorrência típica em áreas de relevo plano ou suavemente ondulados. Devido a essas características esses solos são naturalmente pouco susceptíveis à erosão.

Ao contrário dos Latossolos, no outro extremo, os Neossolos ocorrem nas áreas de cabeceira e limite da sub-bacia, juntamente aos divisores de água, regiões naturalmente mais altas. Os Neossolos Litólicos são solos pouco desenvolvidos, rasos e situam-se em áreas de relevo forte, ondulado a montanhoso, sendo naturalmente mais propensos a ocorrência de processos erosivos (EMBRAPA, 2006).

Tabela 4: Grau de vulnerabilidade natural da sub-bacia do rio Piracicaba/MG em relação a declividade.

\begin{tabular}{|l|l|}
\hline Classes de Declividade (\%) & Pesos \\
\hline$<20$ & 1 \\
\hline $20-45$ & 2 \\
\hline $45-60$ & 3 \\
\hline $60-100$ & 4 \\
\hline$>100$ & 5 \\
\hline
\end{tabular}

Fonte: Santos (2014).

Em relação à declividade, as classes foram estratificadas conforme o grau de inclinação da área, de modo que regiões com menores inclinações receberam os menores pesos e aquelas com maiores inclinações 
receberam os maiores pesos, demonstrando o grau de estabilidade em relação a processos erosivos da área, conforme a tabela 4. A figura 5 representa o mapa do índice de vulnerabilidade para a variável declividade.

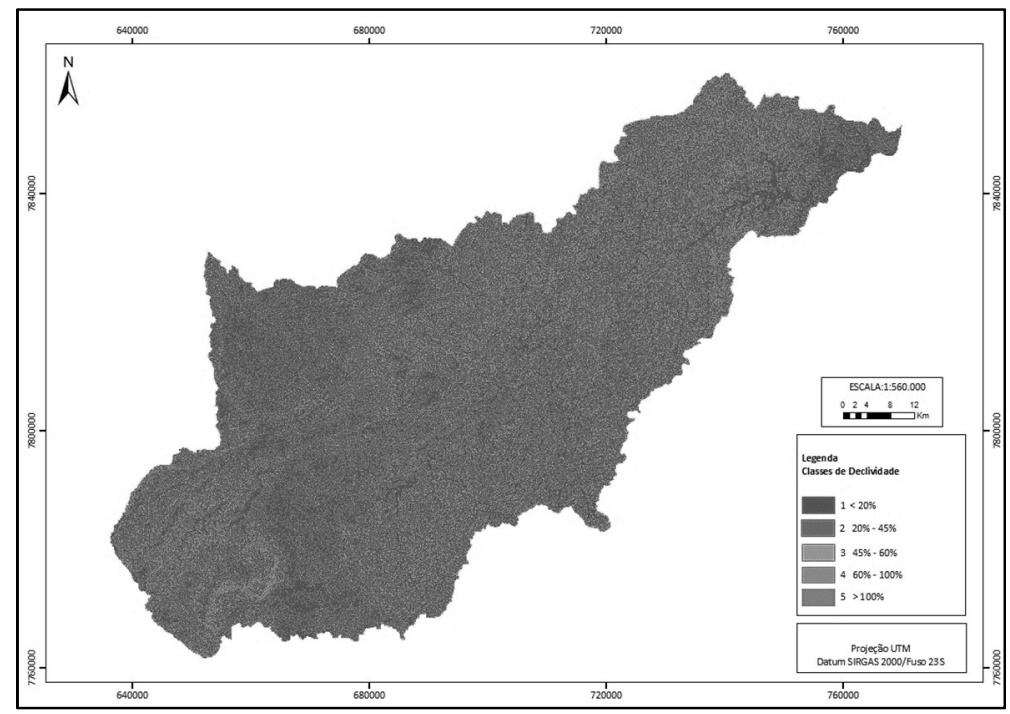

Figura 5: Mapa do índice de vulnerabilidade para a variável declividade da sub-bacia hidrográfica do rio Piracicaba/MG.

No que tange à variável declividade, nota-se que a sub-bacia do rio Piracicaba/MG encontra-se quase que em sua totalidade nas classes 1 e 2 que variam entre $0 \%$ e $45 \%$. Apenas em áreas pontuais são observadas elevadas declividades, é o caso da porção próxima das nascentes do rio Piracicaba e demais partes altas da bacia, nas quais, de acordo com o CBH-Doce (2010) o relevo é acidentado, com altitudes que variam de 1.100 a 1.700 metros, e apresenta vales encaixados e vertentes ravinadas. Em relação à cobertura vegetal, a hierarquização das classes obtidas foi feita conforme tabela 5. A figura 6 representa o mapa do índice de vulnerabilidade para a variável cobertura vegetal.

Tabela 5: Grau de vulnerabilidade natural da sub-bacia do rio Piracicaba/MG em relação a cobertura vegetal.

\begin{tabular}{|l|l|}
\hline Classes de Cobertura Vegetal & Pesos \\
\hline Mata & 1 \\
\hline Afloramento Rochoso & 2 \\
\hline Agrossilvopastoril & 3 \\
\hline Área Urbana & 4 \\
\hline Solo exposto/Mineração & 5 \\
\hline
\end{tabular}

Fonte: Adaptado de Lopes (2015) e Nascimento et al. (2016).

As classes de cobertura vegetal mais expressivas encontradas são as áreas de mata e os sistemas agrossilvopastoris, precedidos de áreas urbanas e de mineração. Destaca-se também que as áreas com maiores valores observados representam as regiões mais antropizadas da bacia, onde há uma maior incidência de atividades de mineração e sistemas agrossilvopastoris que tem como uma das suas principais características a remoção da camada superficial de proteção do solo, causando uma maior heterogeneidade da paisagem.

A sub-bacia do rio Piracicaba/MG, encontra-se intensamente antropizada, sendo o mapa de vulnerabilidade natural em relação à cobertura vegetal, um reflexo desta situação. De acordo com o CBHDoce (2010), em relação à distribuição dos Sistemas Naturais e Antrópicos, esta bacia possui 60\% de sua área 
formada por sistemas antropizados e $40 \%$ em estágio natural, ou próximo a este. Segundo Queiroz (2000), a bacia teve um aumento na taxa de urbanização em função da presença de indústrias de extração mineral, siderurgia e silvicultura para produção de carvão e celulose, sendo que a expansão urbana tem ocorrido em áreas de relevo acidentado e de várzeas, causando a erosão e assoreamento dos rios, dentre outros distúrbios.

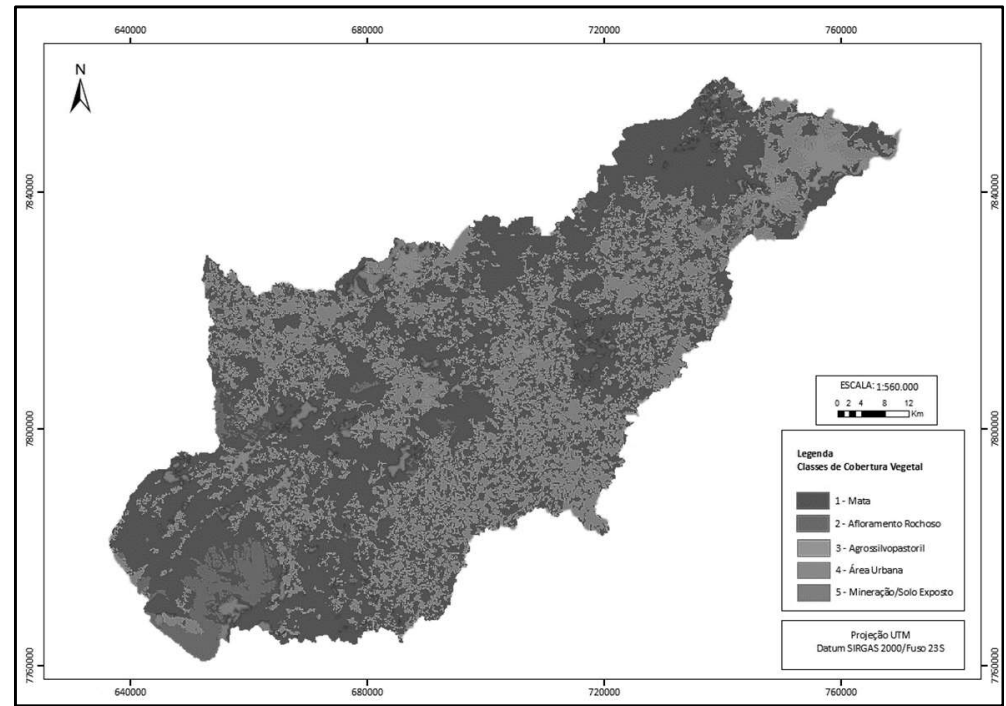

Figura 6: Mapa do índice de vulnerabilidade para a variável cobertura vegetal da sub-bacia hidrográfica do rio Piracicaba/MG.

Ressalta-se que os sistemas agrosilvopastoris também são uma intervenção antrópica. Além de que, a incorporação das áreas de silvicultura em áreas que anteriormente eram de mata, pode ter favorecido a grande expressão dessas áreas na bacia. Ainda, de acordo com o CBH-Doce (2010), no Estado de Minas Gerais, os municípios são afetados por problemas de intensa exploração e degradação da vegetação natural, sendo que grande parte da vegetação natural tem sido substituída por pastagens exóticas.

A exploração mineral, aqui incorporada na classe solo exposto, constitui prática comum ao longo da sub-bacia e apresenta impactos ambientais importantes, como destruição de paisagens, erosão dos solos e assoreamento de córregos, rios e lagos CBH-Doce (2010). Com a interseção das variáveis apresentadas foi gerado o mapa de vulnerabilidade natural da sub-bacia do rio Piracicaba/MG (Figura 7).

A sub-bacia do rio Piracicaba/MG, foi enquadrada em sua maior parte às classes de vulnerabilidade natural 1, 2 e 3 (muito fraca, fraca e média). Observa-se ainda, que as classes de vulnerabilidade mais altas encontradas estão localizadas principalmente no alto curso do rio Piracicaba, o que corrobora com os resultados parciais, uma vez que, especialmente nos mapas de índice de vulnerabilidade para as variáveis geologia e pedologia observa-se claramente que as áreas mais vulneráveis encontram-se localizadas no alto curso do rio.

De acordo com o CBH-Doce (2010), as áreas de cabeceira da bacia são mais críticas em relação à susceptibilidade a erosão. Isso ocorre em função de um conjunto de fatores naturais, como por exemplo, a geologia do local e a elevada declividade, o que faz com que os solos dessa região sejam menos desenvolvidos e mais rasos, e consequentemente mais propensos a processos erosivos. Aliado a tais fatores destaca-se ainda, a presença da atividade de exploração minerária e antropização de ambientes naturais. 


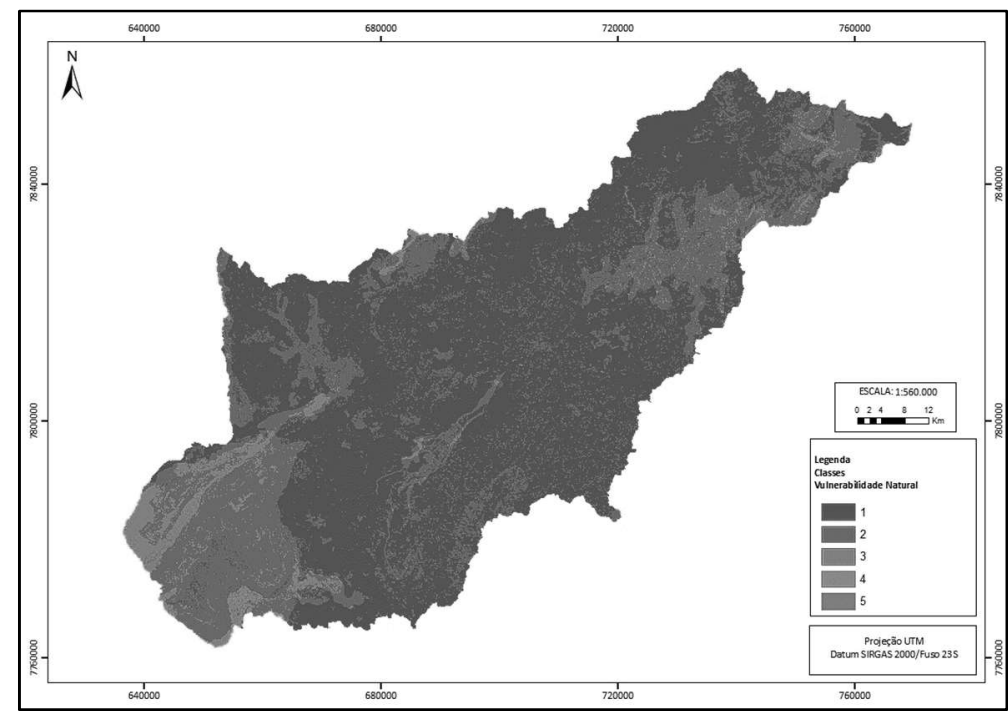

Figura 7: Mapa de vulnerabilidade natural da sub-bacia hidrográfica do rio Piracicaba/MG.

Neste contexto, verifica-se a necessidade de preservação ambiental e planejamento das intervenções a serem realizadas nesta porção da sub-bacia, uma vez que, se trata de uma área com elevada vulnerabilidade e de extrema importância, para preservação dos recursos hídricos. De acordo com o CBHDoce (2010) a cabeceira da bacia já é considerada uma área prioritária para conservação da biodiversidade.

\section{CONCLUSÕES}

Os resultados obtidos permitem apontar algumas considerações importantes sobre a análise realizada na sub-bacia do rio Piracicaba/MG, conforme demonstrado nos mapas gerados, sendo que a metodologia utilizada permitiu identificar as áreas de maior vulnerabilidade natural na sub-bacia. É importante destacar que embora os resultados se mostrem consistentes com o emprego das variáveis selecionadas, existem diversas metodologias que contam com outros elementos, e pesos que poderiam ser também empregados para uma outra análise da vulnerabilidade com uma abordagem diferente. Por meio deste estudo foi possível constatar que o alto curso do rio principal da bacia é a área que apresenta maior vulnerabilidade natural, sendo recomendável maior atenção à sua preservação ambiental, visto a importância dessa área para toda bacia, uma vez que, a nascente do rio principal está localizada nessa área.

Ademais, ressalta-se que estudos nesse sentido fornecem subsídios para identificação dos ambientes naturais, e suas fragilidades potenciais proporcionando uma melhor definição das diretrizes e ações a serem implementadas no espaço, servindo de base para o zoneamento e fornecendo subsídios a gestão da bacia. Por essa razão, os estudos envolvendo essa temática constituem uma importante ferramenta de apoio ao planejamento e a gestão eficiente das bacias hidrográficas, bem como para a conservação dos recursos naturais ali presentes, identificando áreas prioritárias para conservação.

\section{REFERÊNCIAS}

BRASIL. Lei n.9.433: Institui a Política Nacional de Recursos Hídricos, cria o Sistema Nacional de Gerenciamento de Recursos Hídricos, regulamenta o inciso XIX do art. 21 da Constituição Federal, e altera o art. 1ำ da Lei no 8.001 , de 13 de março de 1990, que modificou a Lei no 7.990, de 28 de dezembro de 1989. Brasília: DOU, 1997.

COSTA NETO, J. F.. Elaboração de mapas de vulnerabilidade natural à erosão como subsídio ao zoneamento ambiental 
em bacias hidrográficas com o uso de geoprocessamento. Revista Brasileira de Espeleologia, Brasília, v.1, n.1, p.52-60, 2010.

CREPANI, E.; MEDEIROS, J. S.; HERNANDEZ FILHO, P.; FLORENZANO, T. G.; DUARTE, V.; BARBOSA, C. C. F.. Curso de sensoriamento remoto aplicado ao zoneamento ecológicoeconômico. São José dos Campos: INPE, 2001.

EMBRAPA. Empresa Brasileira de Pesquisa Agropecuária. Sistema Brasileiro de Classificação de Solos. Rio de Janeiro: EMBRAPA, 2006.

MEDEIROS, R. B.; PINTO, A. L.; MIGUEL, A. E.; OLIVEIRA, G. H.. Avaliação da vulnerabilidade ambiental na área do assentamento São Joaquim, Selvíria/MS. Caminhos de Geografia, Uberlândia, v.15, n.49, p.126-137, 2014.

NASCIMENTO, N. S.; VIEIRA, E. M.; GONÇALVES, J. A. C.; CUNHA, G. P. Q.. Estudo da vulnerabilidade ambiental em uma micro bacia hidrográfica empregando hierarquia nominal e operador local. Revista Brasileira de Geografia Física, Recife, v.9, n.3, p.897-916, 2016.

CBH DOCE. Comitê de Bacia Hidrográfica do Rio Doce. Plano Integrado de Recursos Hídricos da Bacia Hidrográfica do Rio Doce. Belo Horizonte: Consórcio Ecoplan Lume, 2010.
QUEIROZ, J. E. N.. Técnicas de Geoprocessamento aplicadas o estudo de bacias hidrográficas: o caso da Bacia do Rio Piracicaba. Monografia (Especialização) - Universidade Federal de Minas Gerais, Belo Horizonte, 2000.

SANTOS, M. F. S.. Geoprocessamento aplicado ao estudo da vulnerabilidade ambiental da Serra da Calçada/MG.

Monografia (Especialização) - Universidade Federal de Minas Gerais, Belo Horizonte, 2014.

SANTOS, R. F.. Temáticas e temas usados em planejamento ambiental. In: SANTOS, R. F.. Planejamento ambiental: teoria e prática. São Paulo: Oficina de Textos, 2009. p.72-108.

SANTOS, R. F.; THOMAZIELLO, S.; WEILL, M. A. M.. Planejamento da paisagem. In: BRASIL. Ministério do Meio Ambiente. Vulnerabilidade Ambiental: Desastres naturais ou fenômenos induzidos?. Brasília: MMA, 2007. p.165-180.

SILVEIRA, T.; REGO, N. A. C.; SANTOS, J. W. B.; ARAÚJO, M. S. B. A.. Qualidade da Água e Vulnerabilidade dos Recursos Hídricos Superficiais na Definição das Fragilidades Potencial e Ambiental de Bacias Hidrográficas. Revista Brasileira de Geografia Física, Recife, v.7, n.4, p.643-652, 2014.

A CBPC - Companhia Brasileira de Produção Científica (CNPJ: 11.221.422/0001-03) detém os direitos materiais desta publicação. Os direitos referem-se à publicação do trabalho em qualquer parte do mundo, incluindo os direitos às renovações, expansões e disseminações da contribuição, bem como outros direitos subsidiários. Todos os trabalhos publicados eletronicamente poderão posteriormente ser publicados em coletâneas impressas sob coordenação da Sustenere Publishing, da Companhia Brasileira de Produção Científica e seus parceiros autorizados. Os (as) autores (as) preservam os direitos autorais, mas não têm permissão para a publicação da contribuição em outro meio, impresso ou digital, em português ou em tradução. 